\title{
PLANT GROWTH PROMOTING ENDOPHYTIC FUNGI ISOLATED FROM TEA (CAMELLIA SINENSIS) SHRUBS OF ASSAM, INDIA
}

\author{
NATH, R. ${ }^{1,2,4}-$ SHARMA, G. D. ${ }^{3}-$ BAROOAH, M. ${ }^{4 *}$ \\ ${ }^{1}$ Dept. of Botany, B.N. College, Dhubri, Assam. \\ ${ }^{2}$ Dept. of Life Science and Bioinformatics, Assam University, Silchar. \\ ${ }^{3}$ Vice Chancellor, Bilaspur University, Chattisgarh, India \\ ${ }^{4}$ Dept. of Agricultural Biotechnology Assam Agricultural University, Jorhat, Assam, India \\ (phone: +91-970-791-4210) \\ *Corresponding author \\ e-mail:m17barooah@yahoo.co.in,rnath286@gmail.com
}

(Received $9^{\text {th }}$ Dec 2014; accepted $3^{\text {rd }}$ Feb 2015)

\begin{abstract}
The present paper deals with isolation of endophytic fungi from root, stem and leaves of tea (Camellia sinensis) shrubs collected from different tea gardens of Assam, India and evaluation of their plant growth promoting activities in vitro. Out of ten different endophytic fungi isolated the highest IAA (indole acetic acid) activity was observed for Aspergillus niger $(36.49 \pm 1.17 \mu \mathrm{g} / \mathrm{ml}$ ) followed by Penicillium sclerotiorum $(36.35 \pm 2.07 \mu \mathrm{g} / \mathrm{ml})$. The highest $\mathrm{GA}_{3}$ activity was exhibited by the fungus Fusarium oxysporum $(12.46 \pm 0.84 \mu \mathrm{g} / \mathrm{ml})$ followed by $P$. chrysogenum $\mathrm{F} 1(10.95 \pm 0.37 \mu \mathrm{g} / \mathrm{ml})$. Evaluation of insoluble mineral solubilization activities of endophytic fungi revealed $P$. sclerotiorum as most efficient phosphate solubilizer $(215.98 \pm 0.2 \mu \mathrm{g} / \mathrm{ml})$, A. niger as the highest potassium solubilizer (solubilization index $1.74 \pm 0.2$ ) and P. sclerotiorum as the most efficient zinc solubilizer. It was also observed that plant growth promoting activities of the fungal endophytes increased up to a certain period of incubation and thereafter it decreased. As these fungal endophytes were found to be efficient in plant growth promoting activities they may have the potential to develop a biofertilizers consortium.
\end{abstract}

Keywords: endophytes, plant growth promoting activities, biofertilizers, mineral solubilization, IAA (indole acetic acid) production

\section{Introduction}

Plant growth promoting microbes are heterogeneous groups of microbes associated with plants in diverse ways. The plant associated microbes colonize the rhizosphere (rhizospheric microbes), the phyllosphere (epiphytes) and inside of the plant tissue (endophytes). The word "endophyte" means "inside the plant" (derived from the Greek words "endon" meaning "within" and "phyton" meaning "plant"). Although there are diverse meanings for the term, endophytes are most commonly defined as those organisms whose "infections are inconspicuous, the infected host tissues are at least transiently symptomless, and the microbial colonization can be demonstrated to be internal" (Stone et al., 2000). In the last decade the study of endophytic microbes has become very important as these microbes are native to the host plants and most of the endophytes are beneficial to the host plants in terms of production of plant growth regulating hormones, solubilization of insoluble minerals and their antagonistic behaviour against plant pathogens and pests. 
Fungal endophytes are low in number in comparison to the bacterial endophytes. Though less in number, they are equally beneficial to the host plants. Most of the fungal endophytes including Aspergillus flavus, A. niger, Fusarium oxysporum, Penicillium corylophilum, P. cyclopium, P. funiculosum and Rhizopus stolonifer isolated from diverse kinds of plants were reported for their ability to produce different kinds of plant growth promoting hormones like indole acetic acid (IAA) and gibberellic acid (GA) Hassan, 2002; Waqas et al., 2012). Similar to the ability to produce plant growth regulating hormones, endophytic fungi were reported well for their mineral solubilizing activities including phosphate, zinc and potassium solubilization. Among the fungal groups Aspergillus and Penicillium are two important endophytic fungal genera having very efficient phosphate solubilizing activity (Wakelin et al., 2004; Souchie et al., 2006). Very few endophytic fungi were reported for their ability to solubilize the insoluble potassium and zinc salts. However, most of the endophytes resemble to their rhizospheric microbial groups and hence such endophytes could be assumed to have zinc and potassium solubilizing activities. Prajapati et al. (2012) isolated four different potassium solubilizing fungi from soils nearby ceramic industries and found that Aspergillus niger and A. terreus possess a greater potassium solubilizing activity.) Aspergillus, Penicillium and Fusarium were reported for their remarkable activity to solubilize different kinds of insoluble mineral salts in rocks including phosphates, zinc and potassium salts (Gaur, 1990; Simine et al., 1998). Lopes-Assad et al. (2010) reported that Aspergillus niger has a better ability to solubilize silicates of potassium and aluminium.

Present day agriculture is based on high inputs of agrochemicals. Over application of chemical fertilizers is one of the major causes of soil and water pollution. More over it is also responsible for depletion of soil quality. To minimize all these environmental problems modern day agriculture should concentrate on organic cultivation through biofertilizers. Though, soil is one of the most common sources for isolation of biofertilizers, adverse effects of soil microbes to plant health is not well known. As endophytes are generally harmless to the plant and have better plant growth promoting activities, manipulation of soil microflora by plant growth promoting endophytes may open a new area in the field organic agriculture.

\section{Materials and Methods}

\section{Collection and preparation of samples}

Root, stem and leaf samples were collected from mature tea (Camellia sinensis) shrubs from different tea gardens of upper Assam, India. Healthy and disease free young root, stem and leaf samples were collected in ice box, packed immediately in poly bags and stored at $4^{0} \mathrm{C}$ for further use.

\section{Isolation of endophytes}

To remove the debris root, stem and leaf samples were washed separately with tap water for seven times followed by distilled water for five times. After proper washing, about five grams of root samples were dipped in $70 \%$ ethanol for five minutes followed by $0.1 \% \mathrm{HgCl}_{2}$ for 1 minute. However, equal amount stem and leaf samples were treated with $70 \%$ alcohol for five minutes followed by $0.05 \% \mathrm{HgCl}_{2}$ for 1 minute. To remove the effect of surface sterilizing agents, samples were washed with sterilized distilled 
water for ten times (Bandara et al., 2006). After proper surface sterilization as well as removal of surface sterilizing agents, samples were homogenized in $50 \mathrm{ml}$ of sterilized distilled water to prepare the stock tissue homogenate. From this tissue homogenate, proper dilution was done according to the standard process of serial dilution. Serially diluted sample tissue homogenates were spread on potato dextrose agar (PDA), Sabouraud Dextrose Agar (SDA) and Czapeck dox agar (CDA) medium (Tejera et al., 2006). Properly inoculated plates were incubated at $25^{\circ} \mathrm{C}$ in an incubator for proper growth of fungal colonies. Single spore technique was used to isolate the pure fungal cultures (Choi et al., 1999). To avoid the unexpected contamination, whole process was done in front of laminar air hood.

Efficacy of the process of surface sterilization was confirmed by rolling a piece of leaf, stem or root on nutrient agar plate and incubated for 24 hours. The plate without any microbial colony after incubation period confirms the proper sterilization of the samples.

\section{Estimation of IAA production}

Quantitative estimation of IAA was performed according to Brick et al. (1991). For this purpose $100 \mathrm{ml}$ of minimal salt (MS) medium were poured into $250 \mathrm{ml}$ Erlenmeyer flasks, autoclaved and allowed to cool at room temperature. All the flasks were amended with filter sterilized L-tryptophan $(1000 \mu \mathrm{g} / \mathrm{ml})$. Flasks were inoculated with 1 $\mathrm{ml}$ of fungal spore suspensions $\left(2 \times 10^{6}\right.$ spores $\left./ \mathrm{ml}\right)$ and incubated at $25^{\circ} \mathrm{C}$. The control flask was incubated without inoculation with spore suspension. Two, four, six and eight days old culture supernatants from each flask were centrifuged at 3,000 rpm for 10 minutes. For measuring the amount of IAA produced, $1 \mathrm{ml}$ of culture supernatant was pipetted into test tubes and mixed with $2 \mathrm{ml}$ of $\mathrm{FeCl}_{3}$-perchloric acid reagent $(50 \mathrm{ml}$ $35 \%$ perchloric acid $+1 \mathrm{ml} 0.5 \mathrm{M} \mathrm{FeCl} 3$ solution) and 2 drops of ortho-phosphoric acid. After 25 mins development of pink colour was measured at $530 \mathrm{~nm}$ wave length by UVVIS spectrophotometer (CECIL CE 7250).

\section{Estimation of Gibberellic acid (GA3)}

Spore suspension of $2 \times 10^{6}$ spores per $\mathrm{ml}$ were directly inoculated into the flasks with $100 \mathrm{ml} \mathrm{MS}$ medium amended with $1000 \mu \mathrm{g} / \mathrm{ml}$ of tryptophan and incubated at $25^{\circ}$ $\mathrm{C}$ up to 6 days. Amount of $\mathrm{GA}_{3}$ present in the culture supernatant was determined according to the standard method forwarded by Uthandi et al. (2010). $30 \mathrm{ml}$ of 6 days old broth culture from each flask were taken and centrifuged at $3000 \mathrm{rpm}$ to remove the particulate matters including fungal hyphae. Twenty five $\mathrm{ml}$ of culture supernatant was taken in to a $40 \mathrm{ml}$ test tube to which $2 \mathrm{ml}$ of zinc acetate (1M) was added. After 2 minutes $2 \mathrm{ml}$ of potassium ferrocyanide was added and centrifuged at $1000 \mathrm{rpm}$ for 15 minutes. To $5 \mathrm{ml}$ of this supernatant, equal volume of 30\% HCL was added slowly and incubated at $20^{\circ} \mathrm{C}$ for 75 minutes. An uninoculated broth was taken as reference and this blank sample was also treated in the same manner and the absorbancy was measured spectrophotometrically at $254 \mathrm{~nm}$ wave length.

\section{Phosphate solubilization}

Screening of fungal isolates for their phosphate solubilizing activity was done in Pikovskya's agar (glucose, $10 \mathrm{~g} / \mathrm{L} ; \mathrm{Ca}_{3}\left(\mathrm{PO}_{4}\right) 2,5 \mathrm{~g} / \mathrm{L} ;\left(\mathrm{NH}_{4}\right)_{2} \mathrm{SO}_{4}, 0.5 \mathrm{~g} / \mathrm{L} ; \mathrm{NaCl}, 0.2$ $\mathrm{g} / \mathrm{L} ; \mathrm{MgSO}_{4} .7 \mathrm{H}_{2} \mathrm{O}, 0.1 \mathrm{~g} / \mathrm{L} ; \mathrm{KCl}, 0.2 \mathrm{~g} / \mathrm{L} ;$ yeast extract, $0.5 \mathrm{~g} / \mathrm{L} ; \mathrm{MnSO}_{4} \mathrm{H}_{2} \mathrm{O}, 0.002$ 
$\mathrm{g} / \mathrm{L}$; and $\mathrm{FeSO}_{4} .7 \mathrm{H}_{2} \mathrm{O}, 0.002 \mathrm{~g} / \mathrm{L}$, agar $15 \mathrm{~g} / \mathrm{L}$ ) medium plates. Isolates showing clear zones around the growing colonies after $72 \mathrm{hrs}$ of incubation at $25^{\circ} \mathrm{C}$ were considered as positive for $\mathrm{P}$ solubilization (Gour, 1990).

Quantitative estimation of phosphate solubilization in broth culture was performed according to the procedure of Jackson (1973). All the fungal isolates were grown seperately in $500 \mathrm{ml}$ conical flasks containing $250 \mathrm{ml}$ of Pikovskya's broth. . One uninoculated flask was used as control. Flasks were incubated at $25^{\circ} \mathrm{C}$ for ten days in a shaking incubator at $250 \mathrm{rpm}$. Five $\mathrm{ml}$ of four, six, eight and ten day's old cultures were centrifuged at 3,000 rpm for $10 \mathrm{mins}$. One $\mathrm{ml}$ of supernatant from each flask was mixed with $10 \mathrm{ml}$ of chloromolybdic acid and the volume was adjusted to $40 \mathrm{ml}$ with distilled water. To this mixture, $1 \mathrm{ml}$ of chlorostannous acid was added. Final volume was made $50 \mathrm{ml}$ by adding distilled water. Absorbance of the developing blue colour was measured at $600 \mathrm{~nm}$ wave length with UV-VIS spectrophotometer (CECIL CE 7250). The amount of soluble phosphate was calculated from standard curve of $\mathrm{KH} 2 \mathrm{PO}_{4}$. Periodic estimation of culture $\mathrm{pH}$ was performed by using digital $\mathrm{pH}$ meter (EUTECH pc 510).

\section{Zinc solubilization}

Screening of endophytic fungi for their zinc solubilization activity was done by using halo zone formation method in Basal medium (glucose-10.0 g/L; ammonium sulphate$1.0 \mathrm{~g} / \mathrm{L}$; potassium chloride-0.2 $\mathrm{g} / \mathrm{L}$; dipotassium hydrogen phosphate-0.1 g/L; magnesium sulphate- $0.2 \mathrm{~g} / \mathrm{L} ; \mathrm{pH} 7.0$ ) plates containing $0.1 \%$ insoluble $\mathrm{ZnO}$ or $\mathrm{ZnS}$ (Venkatakrishnan et al. 2003). Solubilization index was calculated by using the standard formula:

$$
\text { Zinc solubilization Index }=\frac{\text { Total diameter of the halo }}{\text { Diameter of the colony }}
$$

\section{Potassium solubilization}

The isolates were screened for their potassium solubilizing activity by halo zone formation method in Aleksandrov agar medium (1\% glucose, $0.5 \%$ Yeast extract, $0.05 \% \mathrm{MgSo}_{4} .7 \mathrm{H}_{2} \mathrm{O}, 0.0005 \% \mathrm{FeCl}_{3}, 0.01 \% \mathrm{CaCO}_{3}, 0.2 \% \mathrm{CaPo}_{4}$ and $3 \%$ agar) containing $0.2 \%$ insoluble potassium bearing mineral; mica (Hu et al. 2006). The plates were incubated at room temperature $\left(30 \pm 1^{\circ} \mathrm{C}\right)$ for 3 days and the colonies exhibiting clear zones around them were considered as positive for potassium solubilization activity. Potassium solubilization index was calculated with the help of following formula.

$$
\text { Potassium solubilization Index }=\frac{\text { Total diameter of the halo }}{\text { Diameter of the colony }}
$$

\section{Extraction of Fungal genomic DNA}

Six days old fungal colonies were collected from PDA plates and ground to fine pastes in an $1.5 \mathrm{ml}$ eppendorf tubes by adding small amount of sterilized sands and 400 $\mu \mathrm{l}$ of fungal lysis buffer (tris $\mathrm{HCl}-50 \mathrm{mM}$; EDTA-50 mM; SDS- 3\%; 3 - 
marcaptoethanol $1 \%$ just before use) to each tube. Centrifuged the mixture for 10 minutes at $12,000 \mathrm{rpm}$ at $4^{\circ} \mathrm{C}$. Transferred the supernatants into new eppendorf tubes and mixed with $300 \mu \mathrm{l}$ of phenol and $300 \mu \mathrm{l}$ of chloroform: isoamyl alcohol (24:1). Shaken well and then centrifuged at $4^{\circ} \mathrm{C}$ with $12000 \mathrm{rpm}$ for 10 minutes. Supernatants were collected into new eppendorf tubes supplemented with $500 \mu 1$ of $99.9 \%(\mathrm{v} / \mathrm{v})$ chilled isopropanol; incubated the mixture at $-20^{\circ} \mathrm{C}$ (minus $20^{\circ} \mathrm{C}$ ) for overnight. Next morning, tubes were centrifuged at $12000 \mathrm{rpm}$ for 10 minutes, discarded the supernatants slowly, washed the pallets gently with $70 \%$ ethanol, air dried for 30 minutes and dissolved the pallets in $30 \mu \mathrm{l}$ tris- EDTA $(1 \mathrm{mM}$ tris $\mathrm{HCl}$ and $1 \mathrm{mM}$ EDTA with $\mathrm{pH} 8.0$ ) individually. Treated the solution with $2 \mu 1$ of RNAse and loaded in $0.8 \%$ agarose gel electrophoresis to confirm the presence of DNA. DNA concentration in the solution was determined with the help of nano-drop DNA quantifier.

\section{Amplification of fungal ITS region}

Amplification of fungal ITS (internal transcribed spacer) was carried out in $25 \mu 1$ PCR reaction mixture (Taq buffer- $2.5 \mu \mathrm{l} ; \mathrm{MgCl}_{2^{-}} 2.0 \mu \mathrm{l} ; 2.5 \mathrm{mM}$ dNTP mix- $2.5 \mu \mathrm{l}$; forward and reverse primer $0.5 \mu 1$ of each; sterilized distilled water- $14 \mu \mathrm{l}$; template DNA- $2 \mu 1$, Taq polymerase $1 \mu \mathrm{l}$ ) using universal ITS 1 (5' CCG AAT TCG TCG ACA ACC TGG TTG ATC CTG CCA GT 3' and ITS 4 (5' CCC GGG ATC CAA GCT TGA TCC TTC TGC AGG TTC ACC T $3^{\prime}$ ) oligonucleotide sequences as forward and reverse primer respectively. DNA was amplified over 35 cycles of PCR profile with $94^{\circ} \mathrm{C}$ for $3 \mathrm{~min}, 94^{\circ} \mathrm{C}$ for $1 \mathrm{~min}, 50^{\circ} \mathrm{C}$ for $30 \mathrm{~s}, 72^{\circ} \mathrm{C}$ for $1 \mathrm{~min}, 72^{\circ} \mathrm{C}$ for $7 \mathrm{~min} 4^{\circ} \mathrm{C}$ for infinity. Amplification of ITS was confirmed by $1.2 \%$ agarose gel electrophoresis and the concentration of DNA was determined by using nano-drop DNA quantifier. The amplified PCR products were sequenced by Sanger dideoxy sequencing method in ABS 3700 sequencer system.

\section{Results}

\section{IAA activity}

Among 10 different fungal endophytes isolated from tea, 8 were found to be efficient IAA producers. Periodic estimation of IAA production of the fungal endophytes revealed that their activity increased gradually up to day 6 and thereafter, decreased (Table 1).

Table 1. IAA activity of fungal endophytes of tea plant.

\begin{tabular}{|l|l|l|l|l|}
\hline \multirow{2}{*}{ Fungal endophytes } & \multicolumn{4}{|c|}{ IAA concentration in $\boldsymbol{\mu g} / \mathbf{m l}$} \\
\cline { 2 - 5 } & Day 2 & Day 4 & Day 6 & Day 8 \\
\hline P. chrysogenum F1 & $8.12 \pm 0.13$ & $17.47 \pm 1.07$ & $28.33 \pm 0.73$ & $21.41 \pm 1.09$ \\
\hline A. fumigatus & $10.09 \pm 0.31$ & $14.26 \pm 2.30$ & $24.55 \pm 0.59$ & $19.92 \pm 1.13$ \\
\hline P. crustosum & $8.06 \pm 0.22$ & $18.35 \pm 1.00$ & $30.62 \pm 1.78$ & $22.94 \pm 1.10$ \\
\hline A. niger & $\mathbf{1 1 . 2 5} \pm \mathbf{0 . 9}$ & $22.89 \pm 1.74$ & $\mathbf{3 6 . 4 9} \pm \mathbf{1 . 1 7}$ & $29.14 \pm 1.36$ \\
\hline P. chrysogenum F5 & $9.176 \pm 0.36$ & $19.9 \pm 1.57$ & $28.33 \pm 1.97$ & $23.32 \pm 0.86$ \\
\hline
\end{tabular}




\begin{tabular}{|l|l|l|l|l|}
\hline P. sp F 7 & $8.73 \pm 1.15$ & $15.76 \pm 0.80$ & $25.51 \pm 0.68$ & $18.58 \pm 0.95$ \\
\hline F. oxysporum & $\mathbf{5 . 1 0} \pm \mathbf{0 . 1 4}$ & $\mathbf{1 3 . 1} \pm \mathbf{0 . 3 9}$ & $20.56 \pm 0.75$ & $17.42 \pm 0.21$ \\
\hline P. sclerotiorum & $10.17 \pm 1.08$ & $25.29 \pm 0.89$ & $36.35 \pm 2.07$ & $33.07 \pm 1.78$ \\
\hline
\end{tabular}

Values are mean \pm SD of three replicates

During the study period, IAA activity ranged between $5.10 \pm 0.14$ and $11.25 \pm 0.9 \mu \mathrm{g} / \mathrm{ml}$ after 2 days; $13.1 \pm 0.39$ and $25.29 \pm 0.89 \mu \mathrm{g} / \mathrm{ml}$ after 4 days; $20.56 \pm 0.75$ and $36.49 \pm 1.17$ $\mu \mathrm{g} / \mathrm{ml}$ after 6 days and $17.42 \pm 0.21$ and $33.07 \pm 1.78 \mu \mathrm{g} / \mathrm{ml}$ after 8 days of incubation. The highest IAA activity was shown by Aspergillus niger $(36.49 \pm 1.17 \mu \mathrm{g} / \mathrm{ml})$ followed by Penicillium sclerotiorum $(36.35 \pm 2.07 \mu \mathrm{g} / \mathrm{ml}), P$. crustosum $(30.62 \pm 1.78 \mu \mathrm{g} / \mathrm{ml})$ and P. chrysogenum F5 $(28.33 \pm 1.97 \mu \mathrm{g} / \mathrm{ml})$ after 6 days of incubation (Fig. 1).

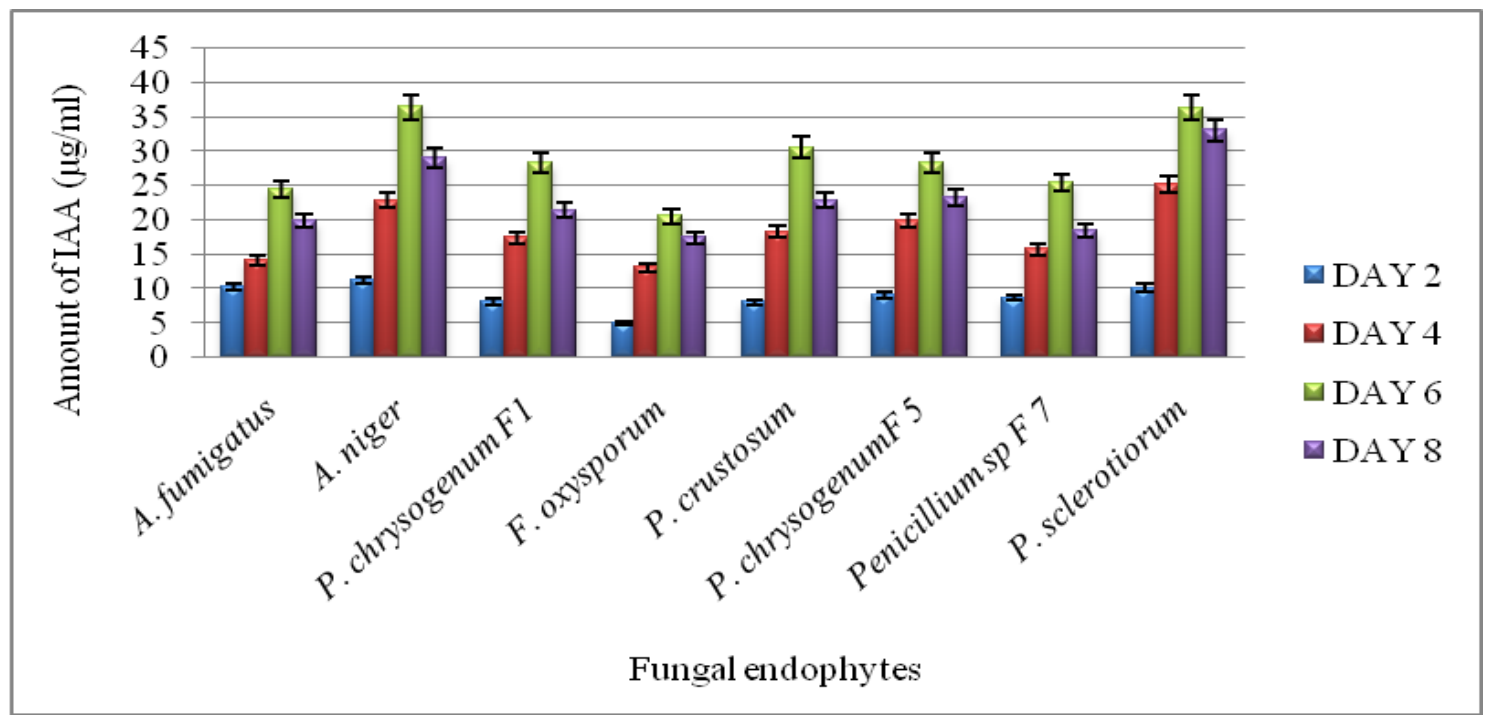

Figure. 1. Indole acetic acid activity of fungal endophytes of tea plant.

\section{$\mathrm{GA}_{3}$ activity}

Estimation of $\mathrm{GA}_{3}$ in the culture supernatant after 6 days of incubation showed that the activity ranged between $6.98 \pm 0.77 \mu \mathrm{g} / \mathrm{ml}$ and $12.46 \pm 0.84 \mu \mathrm{g} / \mathrm{ml}$. The highest $\mathrm{GA}_{3}$ activity was exhibited by Fusarium oxysporum $(12.46 \pm 0.84 \mu \mathrm{g} / \mathrm{ml})$ followed by Penicillium chrysogenum $\mathrm{F} 1(10.95 \pm 0.37 \mu \mathrm{g} / \mathrm{ml})$, Aspergillus fumigatus $(10.04 \pm 0.20 \mu \mathrm{g} / \mathrm{ml})$, A. niger $(9.87 \pm 0.12 \mu \mathrm{g} / \mathrm{ml})$ and $P$. sclerotiorum $(9.86 \pm 0.30 \mu \mathrm{g} / \mathrm{ml})$ (Table 2; Fig. 2).

Table 2. GA3 activity of fungal endophytes of tea plant.

\begin{tabular}{|l|l|}
\hline Fungal endophytes & Amount of $\mathbf{G A}_{\mathbf{3}}$ in $\boldsymbol{\mu g} / \mathbf{m l}$ \\
\hline Penicillium chrysogenum F1 & $10.95 \pm 0.37$ \\
\hline Aspergillus fumigatus & $10.04 \pm 0.20$ \\
\hline Penicillium crustosum & $8.71 \pm 0.54$ \\
\hline
\end{tabular}




\begin{tabular}{|l|l|}
\hline Aspergillus niger & $9.87 \pm 0.12$ \\
\hline Penicillium chrysogenum F5 & $6.98 \pm 0.77$ \\
\hline Penicillium sp F 7 & $7.17 \pm 0.23$ \\
\hline Fusarium oxysporum & $\mathbf{1 2 . 4 6} \pm 0.84$ \\
\hline Penicillium sclerotiorum & $9.86 \pm 0.30$ \\
\hline
\end{tabular}

Values are mean \pm SD of three replicates

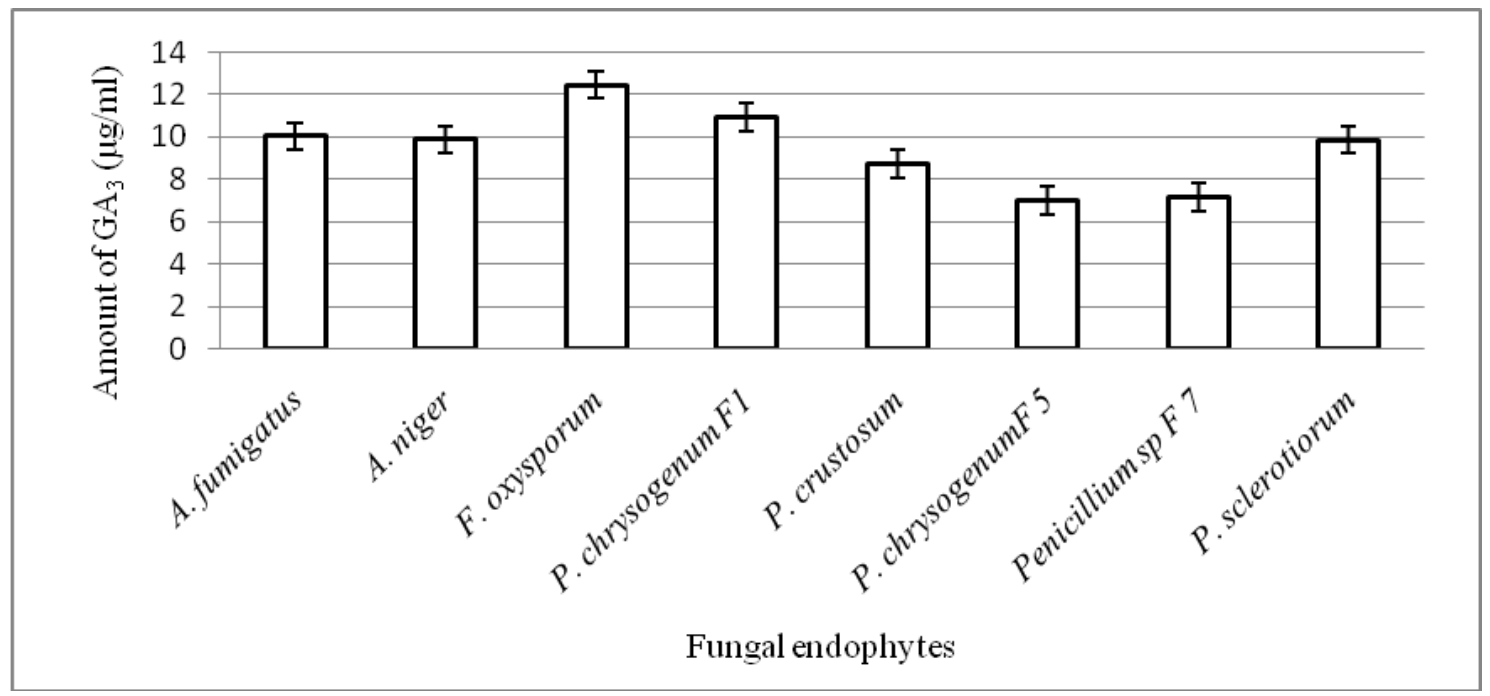

Figure 2. $\mathrm{GA}_{3}$ activity of fungal endophytes of tea plant.

\section{Phosphate solubilizing activity}

Phosphate solubilizing enzyme activity of the fungal endophytes was carried out up to 10 days. It was observed that the enzyme activity increased and reached a maximum on day 8 thereafter, there was gradual decrease (Table 3).

Table 3. Phosphate solubilizing activity of fungal endophytes of tea plant.

\begin{tabular}{|l|l|l|l|l|l|l|l|l|}
\hline \multirow{3}{*}{ Fungalendophytes } & \multicolumn{7}{|c|}{ Amount of phosphate released (in $\boldsymbol{\mu g}$ /mI } \\
\cline { 2 - 9 } & \multicolumn{2}{|c|}{ Day 4 } & \multicolumn{2}{|c|}{ Day 6 } & \multicolumn{2}{c|}{ Day 8 } & \multicolumn{2}{c|}{ Day 10 } \\
\cline { 2 - 9 } & Soluble P & $\mathrm{pH}$ & Soluble P & $\mathrm{pH}$ & Soluble P & $\mathrm{pH}$ & Soluble $\mathrm{P}$ & $\mathrm{pH}$ \\
\hline P. chrysogenum F1 & $49.90 \pm 2.7$ & $5.2 \pm 0.1$ & $63.28 \pm 2.0$ & $4.06 \pm 0.05$ & $86.1 \pm 0.9$ & $3.3 \pm 0.1$ & $80.55 \pm 0.7$ & $4.50 \pm 0.3$ \\
\hline A. fumigatus & $67.83 \pm 1.9$ & $5.11 \pm 0.1$ & $132.75 \pm 2.0$ & $5.32 \pm 1.05$ & $167.35 \pm 1.9$ & $3.49 \pm 0.2$ & $134.5 \pm 2.1$ & $4.21 \pm 0.1$ \\
\hline P. crustosum & $47.35 \pm 1.9$ & $20.63 \pm 0.1$ & $72.43 \pm 2.1$ & $4.55 \pm 0.1$ & $84.23 \pm 1.2$ & $3.53 \pm 0.1$ & $75.25 \pm 1.2$ & $4.6 \pm 0.01$ \\
\hline A. niger & $87.25 \pm 2.2$ & $5.4 \pm 0.1$ & $146.44 \pm 1.7$ & $5 \pm 0.1$ & $170.25 \pm 1.2$ & $3.86 \pm 0.01$ & $143.59 \pm 0.9$ & $4.62 \pm 0.3$ \\
\hline P. chrysogenum F5 & $72.55 \pm 2.0$ & $5.26 \pm 0.1$ & $116.66 \pm 2.0$ & $5.58 \pm 0.5$ & $137.41 \pm 1.7$ & $3.9 \pm 0.02$ & $116.36 \pm 1.8$ & $3.29 \pm 0.2$ \\
\hline Penicillium sp F 7 & $91.8 \pm 3.8$ & $5.63 \pm 0.05$ & $157.50 \pm 0.7$ & $4.52 \pm 0.1$ & $193.02 \pm 1.5$ & $3.99 \pm 0.08$ & $136.33 \pm 1.7$ & $3.30 \pm 0.3$ \\
\hline F. oxysporum & $68.33 \pm 1.6$ & $5.8 \pm 0.1$ & $125.56 \pm 1.2$ & $4.73 \pm 0.1$ & $146.26 \pm 0.8$ & $3.415 \pm 0.4$ & $128.82 \pm 1.6$ & $4.84 \pm 0.9$ \\
\hline C. gossypiicola & $59.9 \pm 1.9$ & $5.63 \pm 0.2$ & $123.72 \pm 1.0$ & $4.05 \pm 0.05$ & $155.43 \pm 1.8$ & $4.35 \pm 1.2$ & $142.49 \pm 1.0$ & $3.82 \pm 0.8$ \\
\hline P. sclerotiorum & $100.33 \pm 2.0$ & $5.01 \pm 0.01$ & $177 \pm 1.7$ & $4.03 \pm 0.02$ & $215.98 \pm 0.2$ & $3.67 \pm 0.02$ & $198.03 \pm 2.3$ & $3.91 \pm 0.4$ \\
\hline
\end{tabular}

Values are mean $\pm \mathrm{SD}$ of three replicates 
Phosphate solubilization activity was measured in terms of amount of soluble phosphate in the culture supernatant. Phosphate solubilization activity ranged between $49.90 \pm 2.7$ and $100.33 \pm 2.0 \mu \mathrm{g} / \mathrm{ml}$ after 4days, $63.28 \pm 2.0$ and $177 \pm 1.7 \mu \mathrm{g} / \mathrm{ml}$ after 6 days; $84.23 \pm 1.2$ and $215.98 \pm 0.2 \mu \mathrm{g} / \mathrm{ml}$ after 8 days and between $75.25 \pm 1.2$ and $198.03 \pm 2.3$ $\mu \mathrm{g} / \mathrm{ml}$ after 10 days of incubation. The highest phosphate solubilization activity was observed for $P$. sclerotiorum $(215.98 \pm 0.2 \mu \mathrm{g} / \mathrm{ml})$ followed by Penicillium $s p$. F 7 $(193.02 \pm 1.5 \mu \mathrm{g} / \mathrm{ml})$, A. niger $(170.25 \pm 1.2 \mu \mathrm{g} / \mathrm{ml})$ and A. fumigates $(167.35 \pm 1.9 \mu \mathrm{g} / \mathrm{ml})$ after 8 days of incubation. Other fungal endophytes also exhibited phosphate solubilization activity. It was also observed that $\mathrm{pH}$ of the medium decreased gradually till day 8 and then slightly increased thereafter. Hence, soluble phosphate in the culture medium increased with a decrease of $\mathrm{pH}$ (Fig. 3) due to the secretion of different organic acids into the medium (Fig. 4).

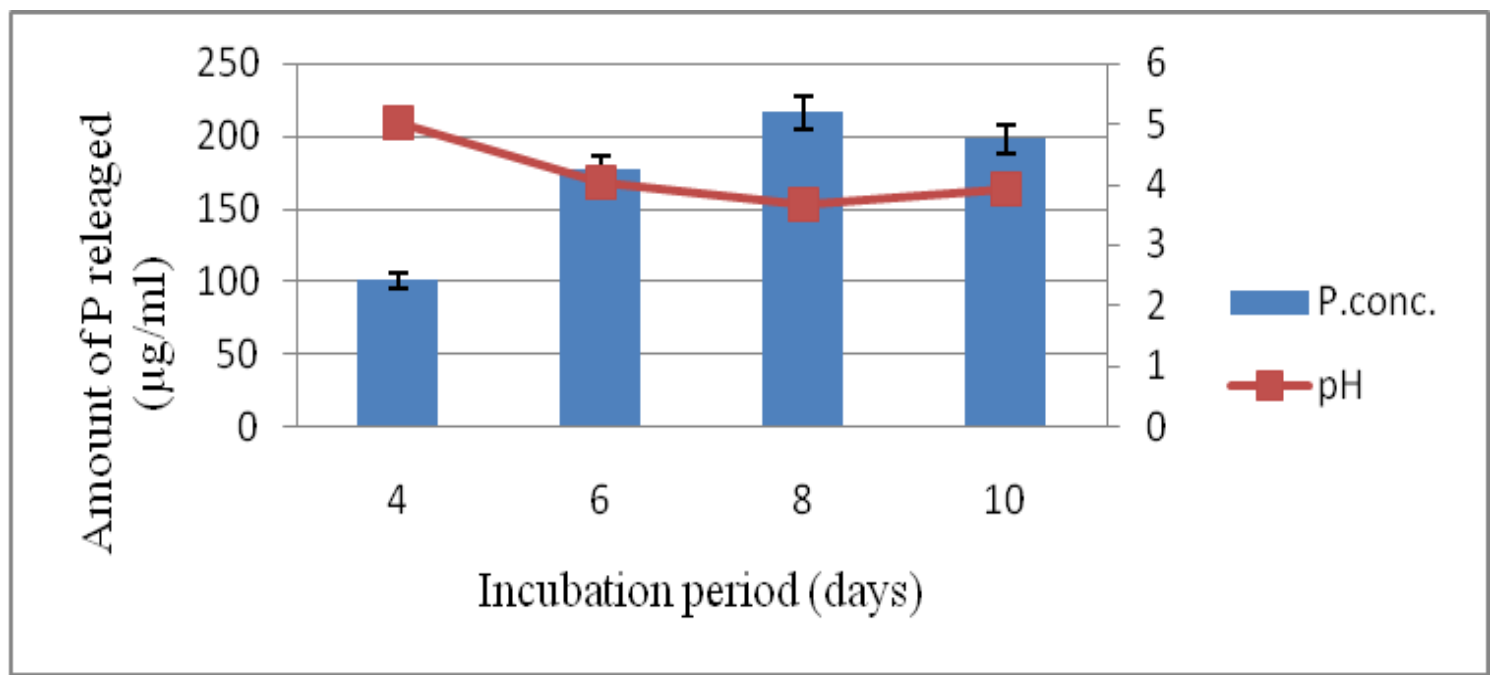

Figure 3. pH drop and phosphate solubilization for P. sclerotiorum

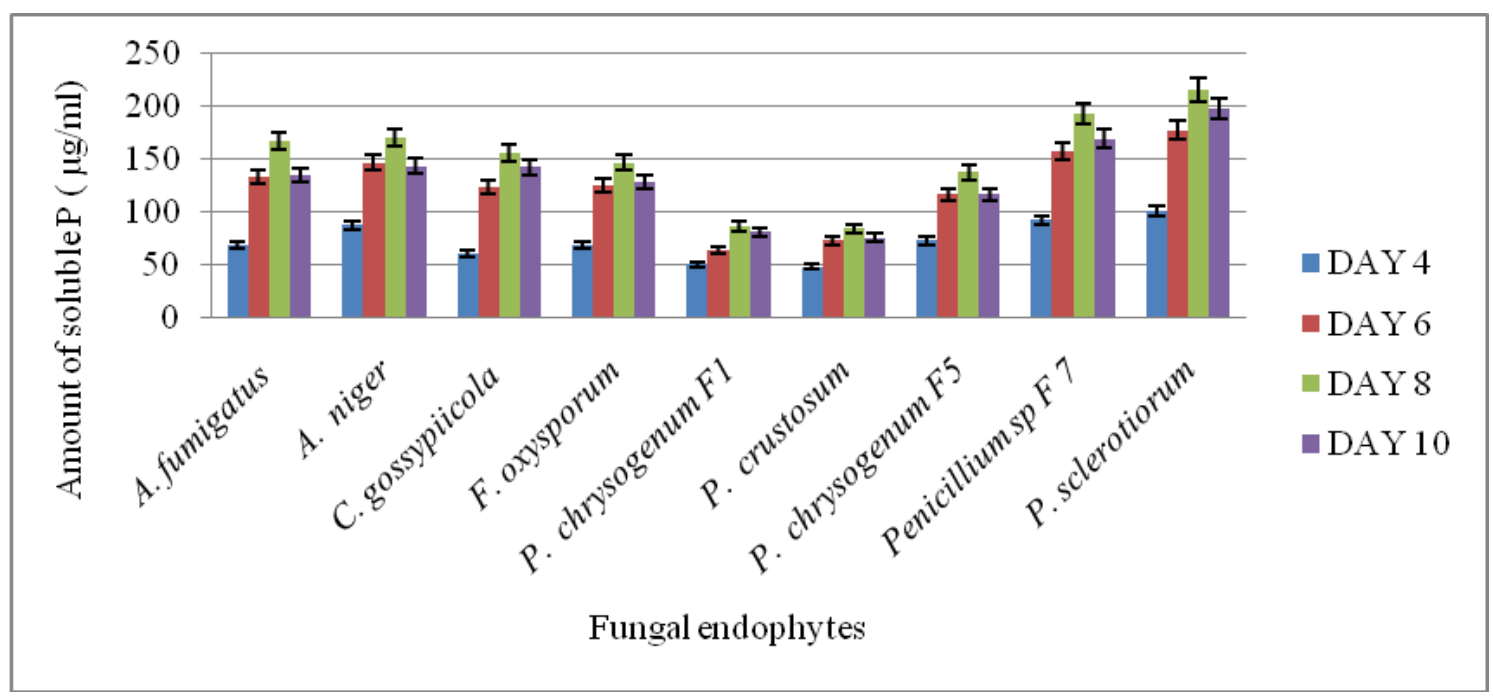

Figure 4. Phosphate solubilizing activity of fungal endophytes of tea plant. 


\section{Zinc solubilizing activity}

Fungal endophytes were screened for their ability to solubilize the insoluble zinc salts in terms of solubilization index through halo zone formation method. Periodic observation of zinc solubilization index for $\mathrm{ZnO}$ and $\mathrm{ZnS}$ revealed that the solubilization index increased gradually up to day 9 and then decreased.

For $\mathrm{ZnO}$, the solubilization index ranged between $0.97 \pm 0.01$ and $1.60 \pm 0.02$ after 3 days; $1.21 \pm 0.01$ and $2.36 \pm 0.04$ after 6 days; $1.4 \pm 0.04$ and $2.87 \pm 0.01$ after 9 days and between $1.24 \pm 0.01$ and $2.66 \pm 0.03$ after 12 days of incubation (Table 4). The highest $\mathrm{ZnO}$ solubilization activity was observed for P. sclerotiorum $(2.87 \pm 0.01)$ followed by Penicillium sp. F 7 (2.22 \pm 0.02$)$, A. niger $(1.96 \pm 0.01)$ and $P$. chrysogenum $F 5$ (1.87 \pm 0.005$)$ after 9 days of incubation period (Table 4; Fig. 5).

Table 4. Zinc solubilization (for $\mathrm{ZnO}$ salt) by the fungal endophytes of tea plant.

\begin{tabular}{|l|l|l|l|l|}
\hline \multirow{2}{*}{ Fungal endophytes } & \multicolumn{4}{|c|}{ Zinc solubilization index for ZnO } \\
\cline { 2 - 5 } & Day 3 & Day 6 & Day 9 & Day 12 \\
\hline P. chrysogenum F1 & $1.27 \pm 0.04$ & $1.36 \pm 0.02$ & $1.75 \pm 0.03$ & $1.60 \pm 0.01$ \\
\hline A. fumigatus & $1.07 \pm 0.04$ & $1.26 \pm 0.01$ & $1.66 \pm 0.01$ & $1.53 \pm 0.01$ \\
\hline P. crustosum & $1.05 \pm 0.06$ & $1.29 \pm 0.005$ & $1.44 \pm 0.01$ & $1.24 \pm 0.01$ \\
\hline A. niger & $1.44 \pm 0.06$ & $1.67 \pm 0.01$ & $1.96 \pm 0.01$ & $1.77 \pm 0.01$ \\
\hline P. chrysogenumF 5 & $1.3 \pm 0.02$ & $1.51 \pm 0.01$ & $1.87 \pm 0.005$ & $1.65 \pm 0.01$ \\
\hline Unidentified & $1.24 \pm 0.02$ & $1.48 \pm 0.02$ & $1.76 \pm 0.01$ & $1.55 \pm 0.01$ \\
\hline Penicillium sp F 7 & $1.47 \pm 0.04$ & $1.74 \pm 0.02$ & $2.22 \pm 0.02$ & $1.94 \pm 0.02$ \\
\hline C. gossypiicola & $0.97 \pm 0.01$ & $1.21 \pm 0.01$ & $1.4 \pm 0.04$ & $1.3 \pm 0.01$ \\
\hline P. sclerotiorum & $1.60 \pm 0.02$ & $2.36 \pm 0.04$ & $2.87 \pm 0.01$ & $2.66 \pm 0.03$ \\
\hline
\end{tabular}

Values are mean $\pm \mathrm{SD}$ of three replicates

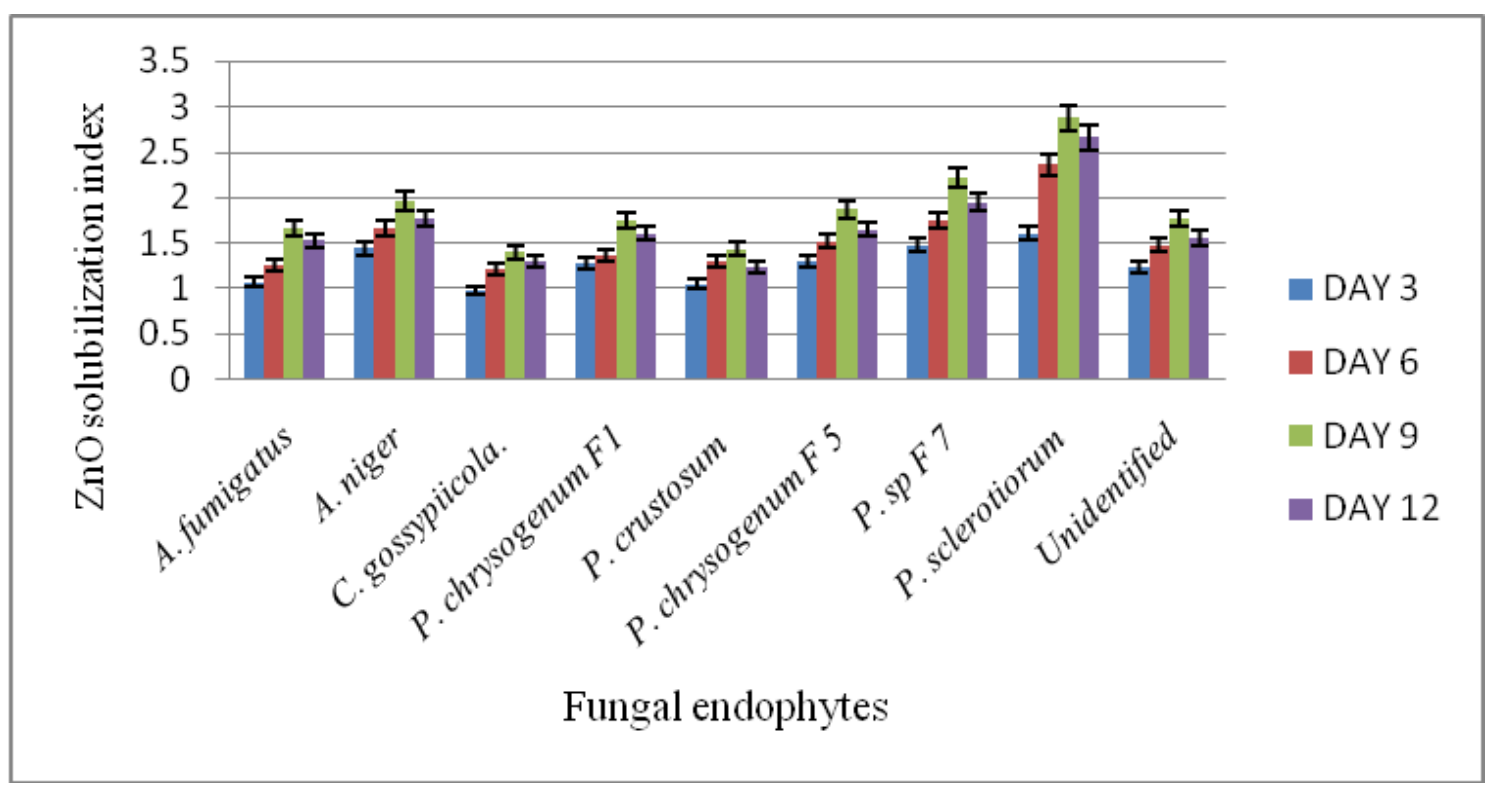

Figure 5. Zinc solubilization (for $\mathrm{ZnO}$ ) activity of fungal endophytes of tea plant. 
The fungal endophytes were able to solubilize $\mathrm{ZnS}$ and the zinc sulphate solubilization activity of fungal endophytes ranged between $1.12 \pm 0.02$ and $1.70 \pm 0.02$ after 3 days; $1.28 \pm 0.01$ and $2.49 \pm 0.03$ after 6 days; $1.56 \pm 0.01$ and $3.29 \pm 0.02$ after 9 days and between $1.3 \pm 0.02$ and $3.04 \pm 0.06$ after 12 days of incubation. The highest $\mathrm{ZnS}$ solubilization index was observed for $P$. sclerotiorum (3.29 \pm 0.02$)$ followed by Penicillium sp. F $7(2.51 \pm 0.04)$, P. chrysogenum F $5(2.09 \pm 0.05)$ and A. niger $(1.96 \pm 0.01)$ after 9 days of incubation (Table 5, Fig. 6).

Table 5. Zinc solubilization (for ZnS salt) by the fungal endophytes of tea plant.

\begin{tabular}{|l|l|l|l|l|}
\hline \multirow{2}{*}{ Fungal endophytes } & \multicolumn{4}{|c|}{ Zinc solubilization index for ZnS } \\
\cline { 2 - 5 } & Day 3 & Day 6 & Day 9 & Day 12 \\
\hline P. chrysogenum F1 & $1.34 \pm 0.01$ & $1.48 \pm 0.03$ & $1.81 \pm 0.03$ & $1.65 \pm 0.02$ \\
\hline A. fumigatus & $1.16 \pm 0.03$ & $1.37 \pm 0.01$ & $1.56 \pm 0.02$ & $1.42 \pm 0.02$ \\
\hline P. crustosum & $1.12 \pm 0.04$ & $1.28 \pm 0.01$ & $1.56 \pm 0.01$ & $1.44 \pm 0.01$ \\
\hline A. niger & $1.54 \pm 0.02$ & $1.74 \pm 0.02$ & $1.96 \pm 0.01$ & $1.74 \pm 0.02$ \\
\hline P. chrysogenum F 5 & $1.41 \pm 0.01$ & $1.68 \pm 0.01$ & $2.09 \pm 0.05$ & $1.87 \pm 0.01$ \\
\hline Unidentified & $1.36 \pm 0.02$ & $1.52 \pm 0.02$ & $1.9 \pm 0.04$ & $1.75 \pm 0.01$ \\
\hline Penicillium sp F 7 & $1.67 \pm 0.02$ & $1.87 \pm 0.02$ & $2.51 \pm 0.04$ & $1.64 \pm 0.5$ \\
\hline C. gossypiicola & $1.12 \pm 0.02$ & $1.34 \pm 0.02$ & $1.56 \pm 0.03$ & $1.3 \pm 0.02$ \\
\hline P. sclerotiorum & $1.70 \pm 0.02$ & $2.49 \pm 0.03$ & $3.29 \pm 0.02$ & $3.04 \pm 0.06$ \\
\hline
\end{tabular}

Values are mean \pm SD of three replicates

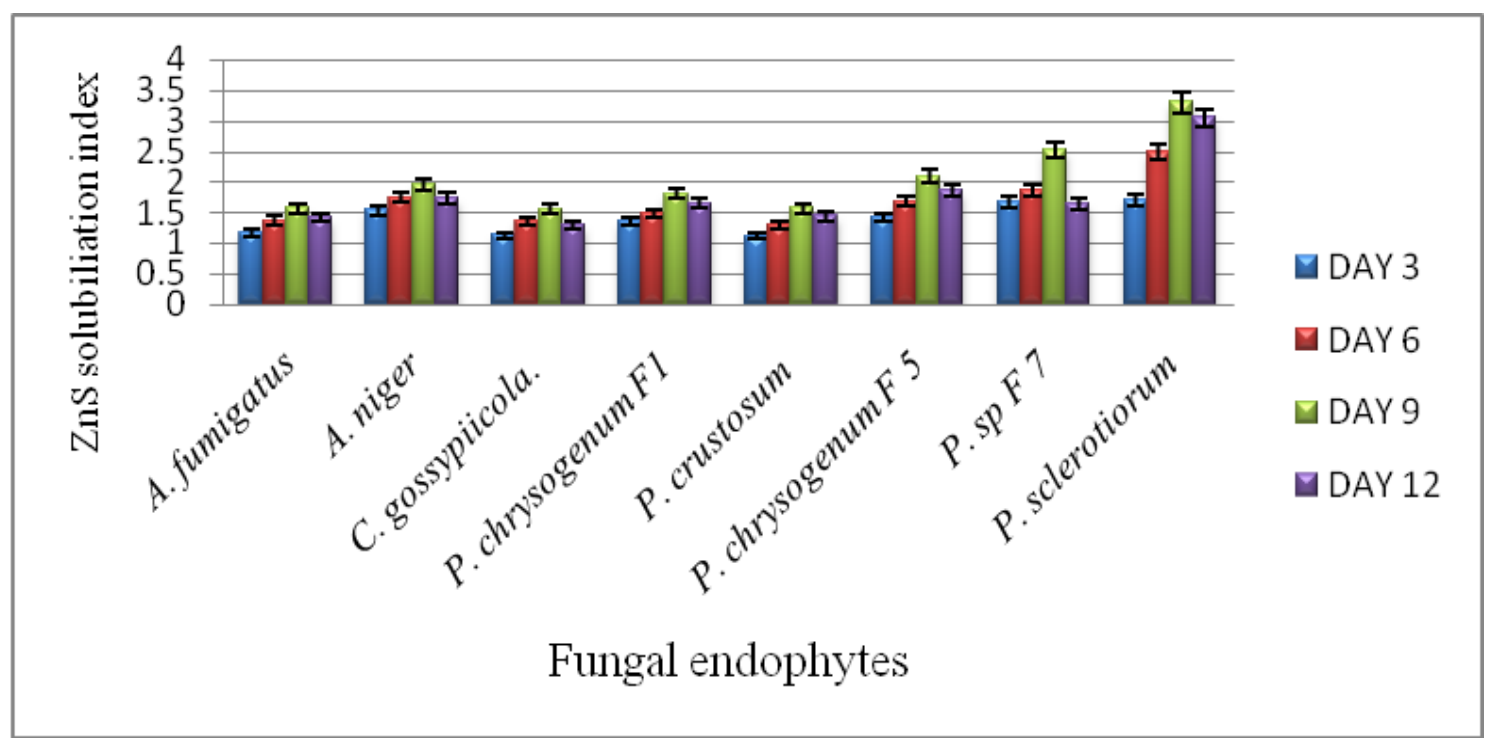

Figure 6. Zinc solubilization (for ZnS) activity of fungal endophytes of tea plant.

\section{Potassium solubilizing activity}

Potassium solubilization activity of the fungal endophytes was estimated by calculating the solubilization index (Table 6). The process of potassium solubilization is a very slow process as revealed by this study. Potassium solubilization index ranged 
between $0.28 \pm 0.05$ and $0.76 \pm 0.06$ after 5 days, $0.95 \pm 0.16$ and $1.50 \pm 0.21$ after 10 days and $1.27 \pm 0.21$ and $1.74 \pm 0.2$ after 15 days. The highest potassium solubilization activity was observed in A. niger (1.74 \pm 0.2$)$ followed by $P$. crustosum $(1.64 \pm 0.16)$ and $P$. chrysogenum F1(1.62 \pm 0.21$)$ after 15 days of incubation. Other fungal endophytes have also exhibited K solubilization activity (Fig. 7).

Table 6. Potassium solubilization by the fungal endophytes of tea plant.

\begin{tabular}{|l|l|l|l|}
\hline \multirow{2}{*}{ Fungal endophytes } & \multicolumn{3}{|c|}{ Potassium solubilization index } \\
\cline { 2 - 4 } & Day 5 & Day 10 & Day 15 \\
\hline P. chrysogenum F1 & $0.53 \pm 0.06$ & $1.27 \pm 0.12$ & $1.62 \pm 0.21$ \\
\hline A. fumigatus & $0.45 \pm 0.04$ & $1.47 \pm 0.34$ & $1.45 \pm 0.24$ \\
\hline P. crustosum & $0.67 \pm 0.08$ & $1.38 \pm 0.12$ & $1.64 \pm 0.16$ \\
\hline A. niger & $0.76 \pm 0.06$ & $1.50 \pm 0.21$ & $1.74 \pm 0.2$ \\
\hline P. chrysogenumF 5 & $0.52 \pm 0.08$ & $0.95 \pm 0.16$ & $1.30 \pm 0.18$ \\
\hline Penicillium sp F 7 & $0.59 \pm 0.03$ & $1.16 \pm 0.11$ & $1.36 \pm 0.17$ \\
\hline F. oxysporum & $0.28 \pm 0.05$ & $0.98 \pm 0.13$ & $1.27 \pm 0.21$ \\
\hline P. sclerotiorum & $0.68 \pm 0.01$ & $1.24 \pm 0.16$ & $1.47 \pm 0.17$ \\
\hline V.us & & & \\
\hline
\end{tabular}

Values are mean $\pm \mathrm{SD}$ of three replicates

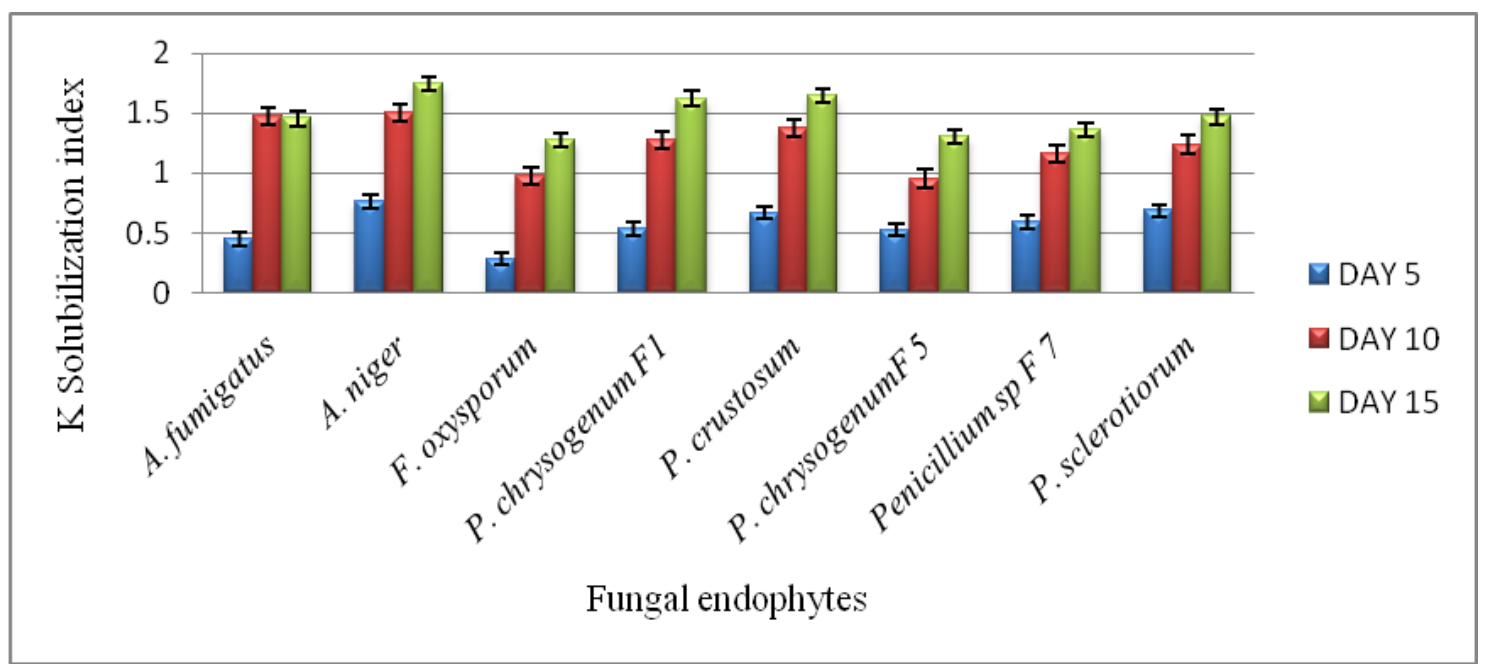

Figure. 7. Potassium solubilization activity of fungal endophytes of tea.

\section{Phylogenetic analysis of the endophytic fungi}

Fungal isolates were characterized at molecular level by amplifying and sequencing their ITS region (Fig. 8). The isolates were identified using similarity percentage through BLAST and sequences were submitted to genbank, NCBI Among the fungal endophytes, different species of Penicillum were found to be predominant. The phylogenetic relationship among them is depicted in Fig. 9. 


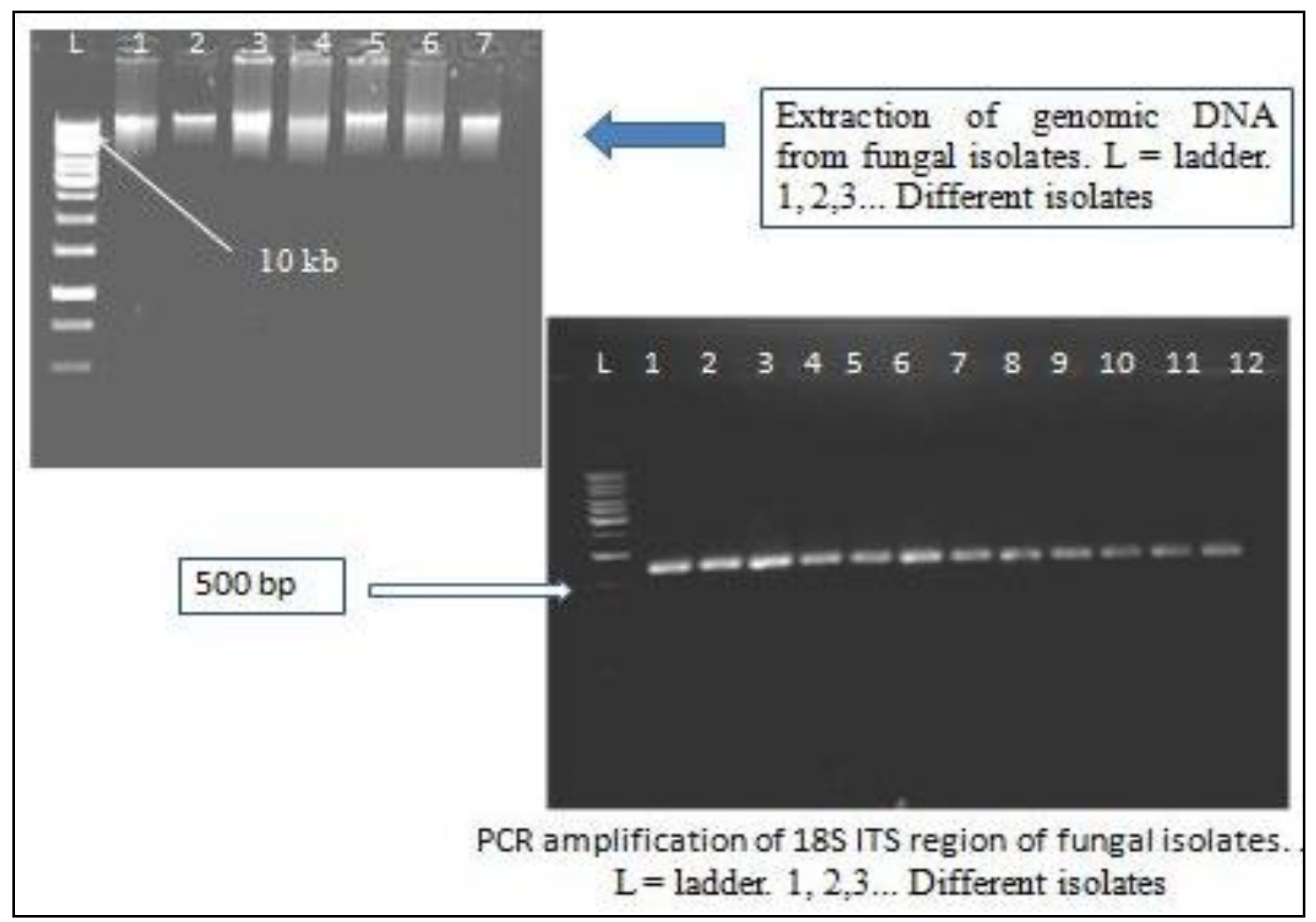

Figure 8. Isolation of genomic DNA from fungal isolates and their ITS amplification in gel.

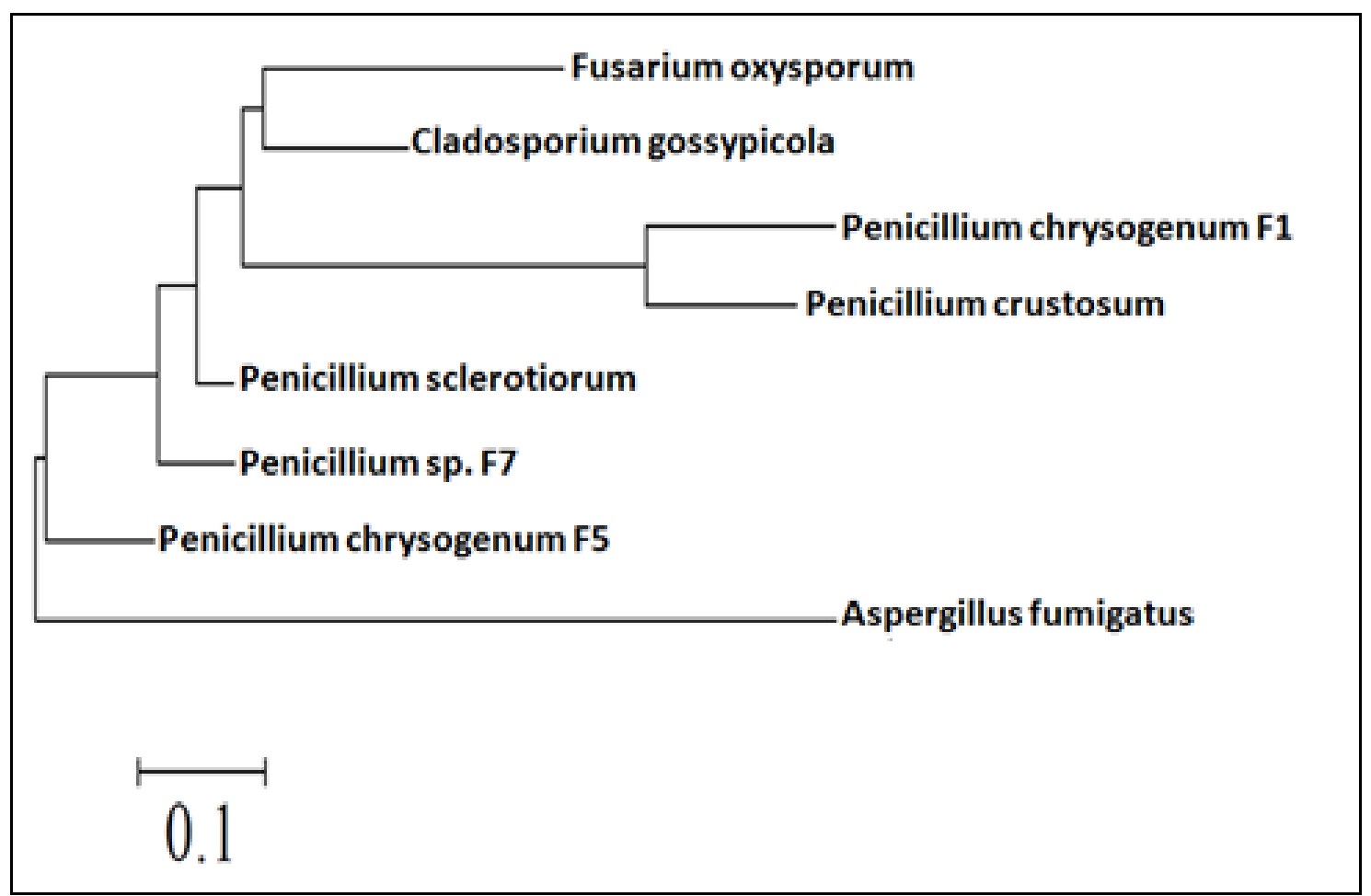

Figure 9. Phylogenetic relationship of endophytic fungi isolated from tea plant 


\section{Discussion}

Plant rhizosphere is the main store house for most of the plant growth promoting microbes. From rhizosphere some microbes which are best compatible to the plant internal environment enter in to the root cortex mainly through the cracks at the site of emergence of lateral roots and then migrate towards the apical parts of the plant body though xylem (Zachow et al., 2010). Most of these endophytes are not only compatible to the host internal environment but have higher plant growth promoting activities in comparison to their rhizospheric partners (Tsavkelova et al., 2007). Hence, exploration of endophytic microbes has a greater opportunity to develop biofertilizers superior to biofertilizers developed from other sources.

The main aim of the present study was to isolate and characterize the fungal endophytes of Camellia sinensis for their plant growth promoting activities in vitro. The results mentioned above depict efficient plant growth promoting activities of the isolated endophytic fungi. In the present study Aspergillus niger was found to be the most efficient in IAA production and potassium solubilization activities. The highest $\mathrm{GA}_{3}$ activity was exhibited by Fusarium oxysporum. Zinc and potassium solubilization activity was observed to be highest in P. sclerotiorum. Hassan (2002) reported some species of Penicillium, Aspergillus and Rhizopus for their IAA and $\mathrm{GA}_{3}$ producing activities. Similarly, Uthandi et al. (2010) reported Fusarium fijikori SG2 as one of the best $\mathrm{GA}_{3}$ producer. Many Trichoderma associated with rhizosphere and endosphere of Calophyllum brasiense were also reported for their plant growth promoting hormone producing and mineral solubilizing activities (Resende et al., 2014). Many bacterial, fungal, yeast, and actinomycetes species capable of solubilizing sparingly soluble phosphorus in pure culture have been isolated and studied (Halder et al., 1991; AbdAlla, 1994; Whitelaw, 2000; Goldstein, 1986). The main mechanism of phosphate and other mineral solubilization is the production of diverse kinds of organic acids that lowers the $\mathrm{pH}$ of the medium causing solubilization of insoluble mineral salts (Ahmad and Jha, 1968). Among phosphate solubilizing fungi species of Aspergillus, Penicillium and yeast have been widely reported for solubilizing various forms of inorganic phosphates (Whitelaw, 2000). Aspergillus niger Penicillium simplicissimum, Penicillium expansum and Scopulariopsis brevicaulis were reported to solubilize the insoluble potassium salts such as potassium aluminosilicates (Sterflinger, 2000). Lots of fungal genera including some ericoid mycorrhizal fungi (mycorrhizal endophytes of Woollsia pungens; Epacridaceae, Hymenoscyphus ericae and Oidiodendron maius) were reported to dissolve hydroxyapatite, $\mathrm{Zn}$ oxide and phosphate (Van Leerdam et al, 2001; Martino et al., 2003). These results are in agreement with the results of the present study. Moreover, the endophytic fungi isolated from Camellia sinensis in the present study were found to be superior in plant growth promoting activities in comparison to the earlier reports. Hence, the fungal endophytes isolated from Camellia sinensis were efficient in plant growth promoting activities and are assumed to be a future source of biofertilizers consortium for Camellia sinensis and other crops.

Acknowledgement. Authors acknowledge the help and supports of all the members of Department Agricultural Biotechnology, Assam Agricultural University, Jorhat, Assam and Department of Life sciences and Bioinformatics, Assam University, Silchar, Assam, for their cooperation and suggestions. The first author is grateful to DST India for the financial support as INSPIRE fellowship. 


\section{REFERENCES}

[1] Abd Alla, M. H. (1994): Phosphatases and the utilization of organic phosphorus by Rhizobium leguminosarum biovar viceae.- Letters of Applied Microbiology 18: 294-296.

[2] Ahmad, N., Jha, K. K. (1968): Solubilization of rock phosphate by microorganism isolated from Bihar soil.- Canadian Journal of Applied Microbiology 14: 89-95.

[3] Bandara, W. M. M. S., Seneviratne, G., Kulasooriya, S. A. (2006): Interactions among endophytic bacteria and fungi: effects and potentials.- Journal of Bioscience 31: 645-650.

[4] Brick, J. M., Bostock, R. M., Sillverstone, S. E. (1991): Rapid insitu assay for indoleacetic acid by bacteria immobilized on nitrocellulose membrane.- Applied and Environmental Microbiology 57: 535-538.

[5] Choi, Y., Kevin, D. H., Wellcome W. H. H. (1999): Single spore isolation of fungi. Fungal Diversity- 3: 29-38.

[6] Goldstein, A. H. (1986): Bacterial solubilization of mineral phosphates: historical perspectives and future prospects. - American Journal of Alternative Agriculture 1: 5157.

[7] Gour, A. C. (1990): Physiological functions of phosphate solubilizing micro-organisms.In: Gour, A .C. (ed.) Phosphate solubilizing micro-organisms as biofertilizers. Omega scientific publishers. New Delhi, 16-72.

[8] Halder, A. K., Mishra, A. K., Chakarbarthy, P. K. (1991): Solubilization of inorganic phosphate by Bradyrhizobium. - Indian Journal of experimental Biology 29: 28-31.

[9] Hassan, H. A. H. (2002): Gibberellin and auxin production by plant root-fungi and their biosynthesis under salinity-calcium interaction.- Rostlinná Výroba 48(3): 101-106.

[10] Hu, X. F., Chen, J., Guo, J. F. (2006): Two phosphate and potassium solubilizing bacteria isolated from Tiannu mountain, Zhejiang, China.- World Journal of Microbiology and Biotechnology 22: 983-990.

[11] Jackson, M. L. (1973): Soil Chemical Analysis. Prentice Hall of India Pvt. Ltd., New Delhi.

[12] Lopes-Assad, M. L., Avansini, S. H., Erler, G., Rosa, M. M., de Carvalho, J. R. P, Ceccato-Antonini S. R. (2010): Rock powder solubilization by Aspergillus niger as a source of potassium for agroecological systems. 19th World Congress of Soil Science.

[13] Martino, E., Perotto, S., Parsons, R., Gadd, G.M. (2003): Solubilization of insoluble inorganic zinc compounds by ericoid mycorrhizal fungi derived from heavy metal polluted sites.- Soil Biology and Biochemistry 35:133-141.

[14] Prajapati, K. B., Modi, H. A. (2012): Isolation and characterization of potassium solubilizing bacteria from ceramic industry soil.- CIBTech Journal of Microbiology 1: 814.

[15] Rosende, M. P., Jakoby, I. C. M. C, Santos, L. C. R., Soares, M. A., Pereira, F. D., Souchie, E. L., Silva F. D. (2014): Phosphate solubilization and phytohormone production by endophytic and rhizosphere Trichoderma isolates of guanandi (Calophyllum brasiense Cambess).- African Journal of Microbiology Research 8 (27): 2616-2623.

[16] Simine, C. D. D., Sayer, J. A., Gadd, G. M. (1998): Solubilization of zinc phosphate by a strain of Pseudomonas fluorescens isolated form a forest soil.-Biology and Fertility of soils 28: 87-94.

[17] Souchie, E. L., Azco, R., Barea, J. M., Saggin-Junior, O. J., Silva, E. M. R. (2006): Phosphate solubilization and synergism between P-solubilizing and arbuscular mycorrhizal fungi.- Pesquisa Agropecuaria Brasileira 41: 1405-1411.

[18] Sterflinger, K. (2000): Fungi as geologic agents.- Geomicrobiology Journal17: 97-124.

[19] Stone, J. K., Bacon, C. W., White, J. F. (2000): An overview of endophytic microbes: Endophytis defined.- In: Bacon, C. W., White, J, F. (ed.) Microbial endophytes, New York: Dekker 3-30. 
[20] Tejera, N., Ortega E., Rodes, R., Lluch, C. (2006): Nitrogen compounds in the apoplastic sap of sugarcane stem: Some implications in the association with endophytes. - Journal of Plant physiology 163: 80-85.

[21] Tsavkelova, E., Cherdyntseva, T., Botina, S., Netrusov, A. (2007): Bacteria associated with orchid roots and microbial production of auxin.- Microesearch 162: 69-76.

[22] Uthandi, S., Karthikeyan, S., Sabarinathan, K. G. (2010): Gibberellic acid production by Fusarium fuzikoroi SG2. -Journal of Scientific and Industrial research 69: 211-214.

[23] Van Leerdam D. M., Williams, P. A., Cairney, J. W. G. (2001): Phosphate-solubilising abilities of ericoid mycorrhizal endophytes of Woolsia pungens (Epacridaceae).Australian Journal of Botany 49:75-80.

[24] Venkatakrishnan, S. S., Subramoniam, S. R., Savariappan, A. R. (2003): Assessing in vitro solubilization potential of different zinc solubilizing bacterial (zsb) isolates.Bobrazilian Journal of Microbiology 34: 121-125.

[25] Wakelin, S. A., Warren, R. A., Harvey, P. R., Ryder, M. H. (2004): Phosphate solubilization by Penicillium spp. closely associated with wheat roots.- Biology and Fertility of Soils 40: 36-43.

[26] Waqas, M., Khan, A. L., Kamran, M., Hamayun, M., Kang, S. M., Kim, Y. H., Lee I. J. (2012): Endophytic Fungi Produce Gibberellins and Indoleacetic Acid and Promotes Host-Plant Growth during Stress. - Molecules 17: 10754-10773.

[27] Whitelaw, M. A. (2000): Growth promotion of plants inoculated with phosphate solubilizing fungi (Ed. Sparks, D. L.). Advances in Agronomy 69: 99-151.

[28] Zachow, C., Fatehi, J., Cardinale, M., Tilcher, R., Berg, G. (2010): Strain-specific colonization pattern of Rhizoctonia antagonists in the root system of sugar beet.-FEMS Microbiology Ecology 74: 124-35. 